\title{
QUALIDADE DA EDUCAÇÃO NAS ESCOLAS PÚBLICAS NO BRASIL: UMA ANÁLISE DA RELAÇÃO INVESTIMENTO POR ALUNO E DESEMPENHO NAS AVALIAÇÕES NACIONAIS
}

\author{
QUALITY OF EDUCATION IN PUBLIC SCHOOLS IN BRAZIL: \\ AN ANALYSIS OF THE CORRELATION BETWEEN \\ INVESTMENT PER STUDENT AND PERFORMANCE IN THE \\ NATIONAL ASSESSMENTS
}

\section{CALIDAD DE EDUCACIÓN EN LAS ESCUELAS PUBLICAS EN BRASIL: UN ANÁLISIS DE LA RELACIÓN ENTRE LA INVERSIÓN POR ESTUDIANTE Y EL RENDIMIENTO EN LAS EVALUACIONES NACIONALES}

\section{Joysi Moraes}

Professora da Universidade Federal Fluminense (UFF), Brasil / Professora convidada da University of Nottingham, Reino Unido / Doutora em Administração pela Universidade Federal do Rio Grande do Sul (UFRGS), Brasil

jmoraes@id.uff.br

Bruno Francisco Batista Dias

Mestre em Administração pela Universidade Federal Fluminense (UFF), em Volta Redonda, Brasil / Especialista com MBA em Gestão Pública com ênfase em didática do ensino superior brunofbd@id.uff.br

\section{Sandra Regina Holanda Mariano}

Professora associada da Universidade Federal Fluminense (UFF) / Mestre e Doutora em Engenharia de Sistemas e Computação pela Universidade Federal do Rio de Janeiro (UFRJ), Brasil sandramariano@id.uff.br
Contextus

ISSNe 2178-9258

Organização: Comitê Científico Interinstitucional Editor Científico: Carlos Adriano Santos Gomes Avaliação: double blind review pelo SEER/OJS

Recebido em 07/04/2017 Aceito em 05/12/2017 $2^{a}$ versão aceita em $20 / 12 / 2017$

\section{RESUMO}

Neste artigo, adotou-se a perspectiva econômica da educação. Esta abordagem assume que a qualidade do ensino pode ser mensurada pela eficácia do uso dos recursos disponíveis. Assim, foi analisada a correlação entre investimento por aluno no ensino fundamental, de 2005 a 2015 (desde o início da série histórica à última avaliação), e os resultados do Índice de Desenvolvimento da Educação Básica (Ideb) de cada estado. Na análise por região (Norte, Nordeste, Centro-Oeste, Sudeste e Sul), as redes de ensino que melhor utilizaram os recursos disponíveis foram as de Roraima, Pernambuco, Goiás, Minas Gerais e Paraná. No ranking nacional, apenas nos estados de Minas Gerais, Pernambuco e Goiás, verificou-se correlação entre a melhoria da aprendizagem dos estudantes, medida pelo Ideb, e o aumento do investimento por aluno.

Palavras-chave: Investimento em educação. Investimento por aluno. Desempenho dos estudantes. Qualidade da educação. Educação básica. 


\begin{abstract}
In this article, we adopted the economic perspective of education. This approach assumes that the quality of education can be measured by the effectiveness of the use of available resources. The correlation between investment per pupil in primary education, from 2005 to 2015 (from the beginning of the historical series to the last evaluation), and the outcome of the students in the evaluation of the Development Index of Basic Education (Ideb) in each state was analyzed. In the analysis per region (North, Northeast, Center-West, Southeast and South), the educational systems that used the available resources in the best manner were those of Roraima, Pernambuco, Goiás, Minas Gerais and Paraná states. Only in the states of Minas Gerais, Pernambuco and Goiás, there was a correlation between the improvement of student learning, as measured by Ideb, and the increase in investment per student.
\end{abstract}

Keywords: Investment in education. Investment per student. Student outcomes. Quality of education. Basic education.

\title{
RESUMEN
}

En este artículo, hemos adoptado el punto de vista económico de la educación. Este enfoque asume que la calidad de la educación se puede medir mediante el uso eficaz de los recursos disponibles. De este modo, se analizó la correlación entre la inversión por estudiante en la educación primaria, de 2005 a 2015 (desde el comienzo de la serie hasta la última evaluación), y los resultados de rendimiento de los estudiantes obtenidos en el Índice de Desarrollo la Educación Básica (Ideb) en cada estado. En el análisis por regiones (Norte, Nordeste, Centro-Oeste, Sudeste y Sur), los sistemas educativos que mejor se utilizaron los recursos disponibles son los de Roraima, Pernambuco, Goiás, Minas Gerais y Paraná. En el ranking nacional, solamente en Minas Gerais, Pernambuco y Goiás, hay correlación entre la mejora de aprendizaje de los estudiantes, medido por el Ideb, y el aumento de la inversión por estudiante.

Palabras-clave: Inversión en educación. Inversión por estudiante. Rendimiento del estudiante. Calidad de la educación. Educación básica.

\section{INTRODUÇÃ̃O}

A expressão "qualidade em educação", no marco dos sistemas educacionais, admite uma variedade de interpretações (econômica, pedagógica, política, social, cultural), a depender da concepção que se tenha sobre o que esses sistemas devem proporcionar à sociedade (DAVOK, 2007; PAWLOWSKI, 2007; ADELSBERGER et al., 2008; VIEBRANTZ; MOROSINI, 2009). Assim, de acordo com Sander (1982, 1995), analisar possíveis resultados dos sistemas educacionais implica pensar e compreender que o próprio sistema de educação, bem como cada escola, é composto por, pelo menos, quatro dimensões passíveis de análise: econômica, pedagógica, política e cultural.

Nesta pesquisa, ativemo-nos à dimensão econômica, ainda pouco explorada no contexto brasileiro, mas que começou a ganhar espaço e força com a criação do Índice de Desenvolvimento da Educação Básica, em 2005. Desde então, passou a ser viável analisar, inclusive comparativamente, o desempenho de cada rede estadual, pública ou particular, bem como de cada escola, a partir das metas de qualidade educacional definidas pelo governo federal para os sistemas educacionais do Brasil.

Isto posto, destaca-se que, para uma abordagem que considera a perspectiva 
econômica, na Economia da Educação, a qualidade da educação pode ser verificada através da eficiência e da eficácia do setor educacional e, na maioria das vezes, dos sistemas educacionais e de suas instituições (DEMO， 1985，2001; SANDER， 1982, 1995; SCRIVEN,1991; SAVIANI, 2001; DAVOK, 2007).

Os conceitos de eficiência e eficácia, sob a perspectiva da racionalidade econômica, presidem as diversas atividades organizacionais e administrativas na educação, tais como a preparação e a execução orçamentária. Assim, a gestão da educação será eficiente na medida em que for capaz de maximizar a utilização de recursos financeiros no sistema educacional, portanto, em suas escolas (COLEMAN et al., 1966; HANUSHEK, 1986, 1994; WÖßMANN, 2000, 2001, 2003; FIGLIO, 1999, 2004). Em outras palavras, a eficiência é o critério econômico que revela a capacidade administrativa de produzir o máximo de resultados com o mínimo de recursos, energia e tempo. A eficácia, por sua vez, é o critério institucional que revela a capacidade administrativa para alcançar as metas estabelecidas ou os resultados propostos (SANDER, 1995).

Portanto, os critérios definidores da dimensão econômica são a eficiência e a eficácia na utilização dos recursos disponíveis, e o que se busca analisar são quais os resultados obtidos nas redes públicas de educação a partir dos investimentos realizados por aluno em cada rede. (HANUSHEK，2005，2012，2013, 2016; HANUSHEK; WÖßMANN, 2007, 2010, 2012). Foi nessa perspectiva que se apoiou a proposta de verificar a relação entre o investimento por aluno na rede pública brasileira e o resultado do desempenho dos mesmos nos exames nacionais de avaliação da qualidade da educação.

Assim, neste artigo, buscou-se analisar a correlação entre investimento educacional por aluno no âmbito do ensino fundamental (anos iniciais e anos finais), considerando o período de 2005 a 2015, ou seja, desde o início da série histórica até a última avaliação, divulgada em 2016, e os resultados de desempenho dos estudantes obtidos nas avaliações nacionais das redes estaduais de ensino.

Foi adotado o Índice de Desenvolvimento da Educação Básica (Ideb) de cada estado como indicador de desempenho dos estudantes, considerando a abrangência nacional desse indicador. $\mathrm{O}$ Ideb incorpora um indicador de fluxo e outro de aprendizagem, que combinados refletem a qualidade do ensino ofertado. 
O investimento por aluno no ensino fundamental (anos iniciais e finais) foi obtido por meio da base dos dados disponibilizados pelo Sistema de Informações sobre Orçamentos Públicos em Educação (SIOPE), desenvolvido pelo Governo Federal, por meio do Fundo Nacional de Desenvolvimento da Educação (FNDE), visando coletar, processar, disseminar e tornar públicas as informações referentes aos orçamentos de educação dos estados, do Distrito Federal e dos municípios. Apesar das imperfeições de tal base de dados, conforme apontam Araújo (2012) e Davies (2013a, 2013b), como subdeclaração dos gastos municipais em educação infantil e educação de jovens e adultos, devido, em parte, ao preenchimento incompleto das informações por municípios e estados, entre outros, é ela a principal base nacional sobre a aplicação da receita vinculada à educação, sendo por isso adotada nesta pesquisa.

Apesar da limitação dos dados disponíveis, os resultados apresentados figuram como um esforço inicial visando correlacionar resultados do investimento em educação e o desempenho estudantil, o que permite apontar tendências e situações, num exercício de contribuir com a discussão a partir da perspectiva dos constructos da Administração, especialmente os que se referem à eficiência e eficácia do uso dos recursos públicos.

\section{FUNDAMENTAÇÃO TEÓRICA}

Em meados da década de 1960, no contexto das lutas pelos direitos civis, o Congresso dos Estados Unidos publicou o relatório Equality of Educational Opportunity (COLEMAN et al., 1966), mais conhecido como Relatório Coleman, que se tornou obra de referência para os estudos da educação e para a construção das políticas públicas de educação. Esse relatório trouxe para o cerne dos debates a questão do investimento público em educação, especialmente no que diz respeito à eficiência do uso destes recursos.

A partir de sua publicação, que foi a primeira pesquisa a relacionar qualidade da educação a resultados de aprendizagem dos estudantes, um dos motivos para ter se tornado referência para estudos a respeito da eficácia das escolas, surgiram diversas pesquisas em educação buscando identificar quais fatores são responsáveis pelo desempenho dos alunos.

$$
\text { É fato que os resultados }
$$
apresentados por Coleman et al., (1966) geraram muita controvérsia, pois questionaram a demanda contínua e crescente por mais recursos financeiros 
como se estes e apenas estes explicassem os resultados das escolas e, portanto, o desempenho dos estudantes em termos de aprendizagem. O Relatório, resultado de uma pesquisa com cerca de 600.000 estudantes, aponta que não é apenas alocando mais recursos financeiros nas escolas que os alunos irão aprender mais ou melhorar seu desempenho. Segundo Coleman et al., (1966), há maior variância intraescola do que interescolas, ou seja, há maior diferença nos resultados da aprendizagem entre os alunos de uma mesma escola do que entre alunos de escolas diferentes. Neste caso, as variações da qualidade de cada escola, individualmente, não influenciariam no sucesso escolar dos seus respectivos educandos.

De acordo com o Relatório Coleman et al., (1966), a escola não conseguiria compensar as desigualdades sociais, reproduzindo em seus resultados as desigualdades encontradas na sociedade da época. "Uma das razões encontradas à época para a descrença na capacidade da escola era a preponderância dos fatores relacionados ao contexto do aluno no seu desempenho escolar" (GUEDES; BAQUEIRO; LORDÊLLO, 2015). Nestes termos, a escola teria apenas um efeito limitado sobre a aprendizagem, seja porque os fatores hereditários ou contextuais eram considerados predominantes, seja porque a escola não poderia competir com a influência decisiva do background familiar durante a primeira infância, seja porque os fatores ambientais não fossem favoráveis (COLEMAN et al., 1966; PLOWDEN, 1967; CHILAND, 1971; JENCKS, 1972).

Um importante estudioso que deu continuidade a estas pesquisas, mas de modo mais específico, buscando relacionar, diretamente, investimentos em educação e resultados dos desempenhos dos estudantes, foi Eric Hanushek. Este pesquisador buscou evidências de que modo os investimentos realizados pelos governos de, pelo menos, 50 países resultariam em melhoria da qualidade das escolas, o que, possivelmente, redundaria, inclusive, em recompensas excepcionais à sociedade, traduzidas pelo crescimento econômico dos países. No entanto, o que Hanushek (1986, 1989, 1994, 2005, 2007, 2013, 2016) observou que os recursos públicos destinados a este setor, muitas vezes, têm sido gastos de maneira inadequada e pouco produtiva, ou seja, não têm contribuído para a melhoria do desempenho dos estudantes. Assim, para Hanushek, Rivkin, Taylor (1996) e Hanushek e Wößmann (2007, 2010) se faz necessário dedicar mais atenção ao uso dos recursos do que ao montante investido. Isto posto que cada escola tenha o mínimo necessário. 
De acordo com Hanushek e Wößmann (2007, p. 14), “infelizmente, análises simples e sofisticadas produzem a mesma resposta: meras políticas de investimentos de recursos que adotam a estrutura já existente das operações escolares não são suficientes para levar a melhorias necessárias na aprendizagem". Do mesmo modo, salientam que os recursos destinados às escolas não podem ser considerados os únicos fatores de impacto no desempenho, mas são fundamentais. Pais, habilidades individuais e amigos, sem dúvida, contribuem para alcance ou não do desempenho adequado. No entanto, as escolas têm um lugar especial no debate porque são as mais diretamente afetadas pelas políticas públicas (HANUSHEK; WÖßMANN, 2012).

Wößmann (2000), a partir de pesquisa realizada com mais de 260.000 estudantes de 39 países (América do Norte, Europa Ocidental e Oriental e Ásia e Israel), já assinalava que o problema da baixa qualidade das escolas públicas era a estrutura do sistema educacional, e não apenas a carência de recursos. Segundo o autor, as diferenças internacionais observadas no desempenho dos estudantes não eram causadas pelos desníveis de recursos educacionais, mas, principalmente, pelas diferenças institucionais dos sistemas educativos. De acordo com os resultados obtidos na pesquisa de Wößmann (2000), os sistemas que, dentre outras coisas, priorizam a autonomia das escolas, estimulam a competição entre elas, permitem aos professores selecionar os métodos didáticos que acreditam ser mais efetivos e estimulam a participação dos pais na vida escolar dos estudantes alcançam melhor desempenho do que sistemas educacionais mais rígidos.

Os pesquisadores não negam que os investimentos são produtivos, posto que seus estudos apontam que alguns níveis mínimos de recursos são necessários e valiosos na promoção da aprendizagem dos alunos. No entanto, destacam que não encontraram relações consistentes ou sistemáticas entre o desempenho dos alunos e variáveis como salários de professores, anos de estudo e/ou de experiência dos docentes, relação entre o número de professores e o número de alunos, e gastos por aluno (HANUSHEK, 2005, 2012).

Como observa Nascimento (2007), “a influência desta corrente se estende até àqueles que, em um primeiro momento de suas análises, tendem a contestá-la, porém, depois, acabam por endossá-la. É o caso de David Figlio (1999, 2004), que atribui, em parte, os resultados pouco significativos encontrados pela corrente majoritária às formas funcionais restritivas utilizadas". 
Entretanto, o próprio David Figlio, em Figlio e Kenny $(2007,2009)$, reconhece que os resultados são, de fato, muito restritos para que se possa defender de forma enfática e com evidências que investimentos maiores em educação se refletem em melhores desempenhos escolares.

Mas, se de um lado, a corrente do mainstream, com embasamento em estudos econométricos apresenta evidências de fatores como maior volume de gastos destinados à educação, melhoria dos salários dos professores e redução do número de alunos por classe, dentre outros, não possuem importância, estatisticamente significativa, para o desempenho dos estudantes, o contraponto a esta linha de pensamento é liderado por Hedges, Laine e Greenwald (1994, 1996a, 1996b). Estes pesquisadores fizeram uma reanálise dos dados coletados por pesquisadores da corrente anterior e as revisaram, segundo os próprios autores, usando métodos de síntese mais sofisticados. O que observaram foram relações sistemáticas positivas entre os recursos e os resultados escolares. Além disso, análises da magnitude dessas relações sugerem que a relação mediana (coeficiente de regressão) é suficiente para ter importância prática. Embora nesta reanálise sugiram que os dados não suportam as conclusões de Hanushek e outros que o seguiram, Hedges, Laine e Greenwald (1994, 1996a, 1996b) destacam que se faz necessário ter cautela no uso do conjunto de dados, especialmente, se estes forem utilizados para a elaboração de políticas públicas.

Card e Krueger (1996), Haurin e Brasington (1996), (Kim, 2001), Deke (2003), Brasington e Haurin (2009), Baker (2016) e outros pesquisadores que buscaram realizar o mesmo tipo de pesquisa em diferentes países acreditam que os resultados apresentados por estudos que deslocam o foco dos testes de rendimento curricular para os efeitos dos recursos escolares nos retornos da educação devem ser cautelosos. Para estes pesquisadores, apenas testes de rendimento ou de aproveitamento escolar como medida de avaliação de desempenho dos estudantes não são suficientes para mensurar a aprendizagem. Os testes de avaliação de desempenho deveriam ser substituídos por resultados de longo-prazo, taxa de evasão, nível salarial de ex-estudantes.

Por último, como ressalta Nascimento (2007, 2008), ainda são poucos os estudos como estes que buscam identificar se existe ou não correlação entre investimentos na educação e desempenho dos estudantes em países latino-americanos. No Brasil, por exemplo, embora o Ideb já 
faça parte da realidade dos gestores das escolas e das redes de escolas públicas, principalmente porque representou uma mudança significativa na forma como a educação passou a ser acompanhada no país, ainda se observa a resistência quanto ao uso desse tipo de indicador (ALVES; SOARES, $\quad 2007 ; \quad$ FERNANDES; GREMAUD, 2009; RIBEIRO; GUSMÃO, 2010, 2013; BROOKE; SOARES, 2008; BROOKE; CUNHA, 2011; TAVARES JÚNIOR; NEUBERT, 2014; WERLE; KOETZ; MARTINS, 2015).

\section{PROCEDIMENTOS METODOLÓGICOS}

A análise apresentada neste estudo foi realizada através do método estatístico de regressão linear. Esse método é uma poderosa ferramenta para identificar a correlação entre variáveis dependente e independente, através da construção de um modelo linear definido pela equação de uma reta ajustada pelo método dos mínimos quadrados (HAIR et. al, 1998).

Neste estudo, o teste de regressão linear teve como propósito identificar a capacidade dos investimentos por aluno na modalidade Manutenção e Desenvolvimento do Ensino (MDE) em influenciar o desempenho médio do Índice de Desenvolvimento da Educação Básica (Ideb) dos anos iniciais e finais do ensino fundamental das redes estaduais no período de 2005 a 2015. A Figura 1 ilustra a relação investigada:

Figura 1 - Relação a ser investigada entre as variáveis

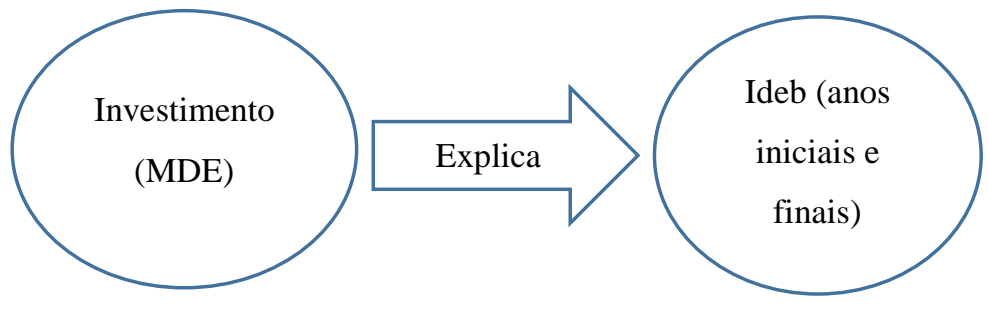

Fonte: desenvolvido pelos autores.

A variável dependente consiste no desempenho do Ideb que assume valores em uma escala contínua de zero a dez. O indicador Ideb, criado em 2007 pelo Instituto Nacional de Estudos e Pesquisas Educacionais (Inep), sintetiza dois conceitos relacionados à qualidade da educação: aprovação e média de desempenho dos estudantes em língua portuguesa e matemática. Seu cálculo é realizado a partir dos dados sobre aprovação escolar, obtidos no Censo Escolar, e médias de desempenho nas avaliações do Inep, o 
Saeb e a Prova Brasil. Conforme declara o Inep (2011, p. 1):

A série histórica de resultados do Ideb se inicia em 2005, a partir de onde foram estabelecidas metas bienais de qualidade a serem atingidas não apenas pelo País, mas também por escolas, municípios e unidades da Federação. A lógica é a de que cada instância evolua de forma a contribuir, em conjunto, para que o Brasil atinja o patamar educacional da média dos países da OCDE. Em termos numéricos, isso significa progredir da média nacional 3,8, registrada em 2005, na primeira fase do ensino fundamental, para um Ideb igual a 6,0 em 2022, ano do bicentenário da
Independência.

O valor definido para o Ideb utilizado no teste estatístico foi ajustado para contemplar tanto os anos iniciais quanto os finais do ensino fundamental. Para tanto, realizou-se o cálculo, conforme Quadro 1, de forma a incluir os valores alcançados no indicador pelos estados brasileiros para as duas modalidades do ensino fundamental:

Quadro 1 - Equação de cálculo da média do Ideb para os anos iniciais e finais do ensino fundamental

$$
I d e b=\frac{I D E B_{\text {Anos iniciais }}+I D E B_{\text {Anos Finais }}}{2}
$$

Fonte: desenvolvido pelos autores.

A variável independente investimento educacional por aluno assume valores contínuos calculados pela média bianual dos recursos, em reais, aplicados à Manutenção e Desenvolvimento do Ensino (MDE). Todos os valores foram corrigidos monetariamente pelo Índice Nacional de Preços ao Consumidor Amplo (IPCA) para 31/12/2015. Como a variável independente
(Ideb) é um indicador bianual e os dados disponíveis para a variável dependente (investimentos) são anuais, ajustou-se esta em relação àquela, daí da utilização do valor médio, de forma que os investimentos correlacionados contemplem o período histórico relativo ao indicador de desempenho. O Quadro 2 descreve o ajuste realizado:

Quadro 2 - Equação de cálculo da média dos investimentos do biênio da realização do Ideb

\begin{tabular}{|l|}
$\qquad G m a_{e a}=\frac{G a_{e a}+G a_{e(a-1)}}{2}$ \\
\hline$G a_{e}=\frac{\text { Investimento gasto com MDE no âmbito do ensino fundamental }}{\text { Número total de alunos matriculados no ensino fundamental }} *(1+\mathrm{i})$ \\
$\mathrm{i}=$ Inflação acumulada no período
\end{tabular}

Fonte: desenvolvido pelos autores. 
Os recursos aplicados à Manutenção

e Desenvolvimento do Ensino (MDE) um conjunto de ações descritas no Quadro

3.

financiam a educação básica, contemplando

Quadro 3 - Composição dos itens financiados na categoria Manutenção e Desenvolvimento do Ensino (MDE)

\begin{tabular}{|l|}
\hline Ações financiáveis \\
\hline $\begin{array}{l}\text { I - Remuneração E aperfeiçoamento do pessoal docente e demais profissionais da educação; por remuneração } \\
\text { devemos entender o total de pagamentos (salário, encargos sociais incidentes e gratificações como: tempo de } \\
\text { serviço, titulação, dentre outras, previstas na lei de cargos e salários) devidos aos profissionais do magistério } \\
\text { da educação, integrantes do quadro de servidores do Estado, Distrito Federal ou Município. }\end{array}$ \\
\hline II - Aquisição, manutenção, construção E conservação de instalações e equipamentos necessários ao ensino; \\
\hline III - Uso e manutenção de bens e serviços vinculados ao ensino; \\
\hline $\begin{array}{l}\text { IV - Levantamentos estatísticos, estudos e pesquisas visando precipuamente ao aprimoramento da qualidade } \\
\text { e à expansão do ensino; }\end{array}$ \\
\hline V - Realização de atividades - meio necessárias ao funcionamento dos sistemas de ensino; \\
\hline VI - Concessão de bolsas de estudo a alunos de escolas públicas e privadas; \\
\hline VII - Amortização e custeio de operações de crédito destinadas a atender ao disposto nos incisos deste artigo; \\
\hline VIII - Aquisição de material didático-escolar e manutenção de programas de transporte escolar. \\
Fonte: Brasil (1996)
\end{tabular}

A base de dados relativa aos investimentos em MDE estão disponíveis no SIOPE. Esse portal foi desenvolvido e elaborado com base nos princípios de finanças públicas, na forma prevista na Constituição Federal, na Lei n. 9394/1996 (LDB), na LC n. 101/2000 (LRF), na Lei n. 11.494/2007 (FUNDEB) e no Decreto Federal n. 6.253/2007. Dentre suas caraterísticas, destaca-se a confiabilidade e o amplo grau de isonomia e comparabilidade entre as informações apresentadas por todos os entes da federação que alimentam o sistema, cujo acesso é restrito ao declarante. A abertura de exceções, ainda que acompanhadas de justificativas formais e específicas, cria precedentes que descaracterizam a padronização e a comparabilidade das informações existentes no sistema, e contrariam as disposições legais, sobre as quais o sistema se alicerça. O SIOPE tem periodicidade anual e prazo para transmissão de dados, cujo cumprimento é condição sine qua non para a realização de transferências voluntarias da União. Assim estabelece o art. $3^{\circ}$ da Portaria do MEC, n.844, de 8 de julho de 2008 (DOC.I), Art. $3^{\circ}$. A partir de $1^{\circ}$ de janeiro de 2009 o preenchimento completo e atualizado do SIOPE pelos Estados, Distrito Federal e Municípios tornou-se condição para a celebração de convênios e termos de cooperação com o Ministério da Educação ou órgãos da administração indireta a ele vinculados.

Face ao exposto, a relação a ser estimada pelo teste de regressão linear correlacionou essas variáveis e os valores por elas assumidos conforme ilustrado no Quadro 4: 
QUALIDADE DA EDUCAÇÃO NAS ESCOLAS PÚBLICAS NO BRASIL: UMA ANÁLISE DA RELAÇÃO INVESTIMENTO POR ALUNO E DESEMPENHO NAS AVALIAÇÕES NACIONAIS

Quadro 4 - Variáveis correlacionadas

\begin{tabular}{|l|l|l|l|l|l|l|l|l|l|l|l|}
\hline $\begin{array}{l}\text { Ano do } \\
\text { Indicador }\end{array}$ & 2005 & 2006 & 2007 & 2008 & 2009 & 2010 & 2011 & 2012 & 2013 & 2014 & 2015 \\
\hline $\begin{array}{l}\text { IDEB } \\
\text { variável }\end{array}$ & Ideb5 & & Ideb7 & & Ideb9 & & Ideb11 & & $\begin{array}{l}\text { Ideb1 } \\
3\end{array}$ & $\begin{array}{l}\text { Ideb1 } \\
5\end{array}$ \\
\hline $\begin{array}{l}\text { Investimento } \\
\begin{array}{l}\text { Siope) } \\
\text { variável }\end{array}\end{array}$ & $\begin{array}{l}\text { Inv- } \\
\mathbf{0 5}\end{array}$ & Inv-6-7 & Inv-8-9 & Inv-10-11 & Inv-12-13 & Inv-14-15 \\
\hline
\end{tabular}

* Diante da inexistência de informações para o ano de 2004, para o ano de 2005 utilizou-se apenas o valor investido por aluno naquele ano.

Fonte: desenvolvido pelos autores.

Essa relação a ser investigada e da equação da reta contida no Quadro 5.

descrita no Quadro 4 está modelada através

Quadro 5 - Equação a ser estimada pelo teste de regressão linear

$$
\alpha_{e a}+\beta_{e} G a_{e a}+\epsilon_{e a}=I D E B_{e a}
$$

Para: $-\infty \leq \alpha \leq+\infty, \forall-\infty \leq \beta \leq+\infty$

Em que:

$I D E B_{e a}=$ desempenho obtido no Ideb pelo estado e no periodo a;

$\alpha_{e n}=$ Constante que que representa a interceptação da reta com o eixo vertical

$\beta_{e}=$ expressa a sensibilidade do desempenho do Ideb a variável Ga

$G a_{e a}=$ média dos gastos por aluno pelo estado "e" do ano a e (a-1)

$\epsilon_{\text {en }}$

= Termo de perturbação do modelo, inclui todos os fatores residuais e possíveis erros de medição

Fonte: desenvolvido pelos autores.

O teste estatístico para obtenção dos

valores dos coeficientes que determinam o

modelo a ser estimado foi realizado com o

auxílio do software Statistical Package for

Social Science (SPSS).

\section{RESULTADOS E DISCUSSÕES}

Conforme apresentado, a construção do modelo resultante do teste estatistico foi realizado pela correlação dos dados do Ideb (Tabela 1) com os investimentos em MDE realizados no periodo (Tabela 2 ).

Tabela 1 - Ideb por estado no ensino fundamental (anos iniciais e finais)

\begin{tabular}{|l|c|c|c|c|c|c|}
\hline Estado & $\mathbf{2 0 0 5}$ & $\mathbf{2 0 0 7}$ & $\mathbf{2 0 0 9}$ & $\mathbf{2 0 1 1}$ & $\mathbf{2 0 1 3}$ & $\mathbf{2 0 1 5}$ \\
\hline Acre & 3,4 & 3,8 & 4,3 & 4,45 & 4,8 & 4,95 \\
\hline Alagoas & 2,7 & 3,0 & 3,0 & 2,95 & 3,2 & 3,6 \\
\hline Amapá & 3,3 & 3,2 & 3,6 & 3,7 & 3,6 & 3,95 \\
\hline Amazonas & 3,0 & 3,6 & 4,05 & 4,35 & 4,5 & 4,95 \\
\hline Bahia & 2,6 & 2,65 & 3,0 & 3,35 & 3,55 & 3,75 \\
\hline Ceará & 3,0 & 3,45 & 3,9 & 4,05 & 4,45 & 5,0 \\
\hline Distrito Federal & 3,85 & 4,15 & 4,65 & 4,65 & 4,7 & 4,8 \\
\hline Espírito Santo & 3,6 & 3,85 & 4,4 & 4,35 & 4,65 & 4,75 \\
\hline
\end{tabular}

(CONTINUA) 
(CONTINUAÇÃO)

\begin{tabular}{|l|c|c|c|c|c|c|} 
Goiás & 3,6 & 3,85 & 4,25 & 4,65 & 5,25 & 5,4 \\
\hline Maranhão & 3,2 & 3,35 & 3,8 & 3,8 & 4,0 & 4,05 \\
\hline Mato Grosso & 3,25 & 4,0 & 4,55 & 4,7 & 4,65 & 5,05 \\
\hline Mato Grosso do Sul & 3,05 & 3,75 & 4,0 & 4,2 & 4,4 & 4,75 \\
\hline Minas Gerais & 4,25 & 4,3 & 4,95 & 5,2 & 5,45 & 5,4 \\
\hline Pará & 2,95 & 2,85 & 3,4 & 3,55 & 3,3 & 3,7 \\
\hline Paraíba & 2,75 & 3,15 & 3,25 & 3,45 & 3,6 & 3,85 \\
\hline Paraná & 4,15 & 4,6 & 4,65 & 4,6 & 5,15 & 5,25 \\
\hline Pernambuco & 2,75 & 3,0 & 3,45 & 3,75 & 3,95 & 4,4 \\
\hline Piauí & 2,6 & 3,15 & 3,6 & 3,85 & 4,0 & 4,2 \\
\hline Rio de Janeiro & 3,3 & 3,35 & 3,55 & 3,75 & 4,15 & 4,4 \\
\hline Rio Grande do Norte & 2,6 & 2,85 & 3,2 & 3,3 & 3,5 & 3,85 \\
\hline Rio Grande do Sul & 3,85 & 4,1 & 4,3 & 4,45 & 4,7 & 4,75 \\
\hline Rondônia & 3,4 & 3,65 & 3,9 & 4,1 & 4,55 & 4,85 \\
\hline Roraima & 3,35 & 3,5 & 3,95 & 4,05 & 4,15 & 4,4 \\
\hline Santa Catarina & 4,2 & 4,4 & 4,6 & 5,2 & 4,9 & 5,3 \\
\hline São Paulo & 4,15 & 4,35 & 4,85 & 4,85 & 5,05 & 5,55 \\
\hline Sergipe & 2,95 & 3,15 & 3,2 & 3,4 & 3,4 & 3,6 \\
\hline Tocantins & 3,5 & 3,9 & 4,2 & 4,4 & 4,4 & 4,4 \\
\hline
\end{tabular}

Fonte: Inep (2016).

Tabela 2 - Média dos Investimentos por aluno por estado no ensino fundamental (anos iniciais e anos finais), atualizados pelo INPC

\begin{tabular}{|l|c|c|c|c|c|c|}
\hline ESTADO & $\mathbf{2 0 0 5} * *$ & $\mathbf{2 0 0 6} \mathbf{2 0 0 7}$ & $\mathbf{2 0 0 8}$ e 2009 & $\mathbf{2 0 1 0}$ e 2011 & $\mathbf{2 0 1 2}$ e 2013 & $\mathbf{2 0 1 4}$ e 2015 \\
\hline Acre & $\mathrm{R} \$ 6.343,82$ & $\mathrm{R} \$ 5.448,13$ & $\mathrm{R} \$ 7.712,80$ & $\mathrm{R} \$ 6.605,87$ & $\mathrm{R} \$ 7.884,89$ & $\mathrm{R} \$ 6.797,51$ \\
\hline Alagoas & $\mathrm{R} \$ 1.314,81$ & $\mathrm{R} \$ 1.417,20$ & $\mathrm{R} \$ 5.766,46$ & $\mathrm{R} \$ 6.771,66$ & $\mathrm{R} \$ 8.522,57$ & $*$ \\
\hline Amapá & $\mathrm{R} \$ 2.963,55$ & $\mathrm{R} \$ 2.755,17$ & $\mathrm{R} \$ 6.970,81$ & $\mathrm{R} \$ 7.533,98$ & $\mathrm{R} \$ 10.100,89$ & $\mathrm{R} \$ 9.118,46$ \\
\hline Amazonas & $\mathrm{R} \$ 2.515,47$ & $\mathrm{R} \$ 2.083,54$ & $\mathrm{R} \$ 3.610,00$ & $\mathrm{R} \$ 3.126,59$ & $\mathrm{R} \$ 5.702,42$ & $\mathrm{R} \$ 6.256,73$ \\
\hline Bahia & $\mathrm{R} \$ 2.580,52$ & $\mathrm{R} \$ 2.032,59$ & $\mathrm{R} \$ 4.165,15$ & $\mathrm{R} \$ 3.666,59$ & $\mathrm{R} \$ 4.681,28$ & $\mathrm{R} \$ 5.036,94$ \\
\hline Ceara* & $\mathrm{R} \$ 5.114,08$ & $\mathrm{R} \$ 5.649,30$ & $\mathrm{R} \$ 8.996,41$ & $\mathrm{R} \$ 6.873,06$ & $\mathrm{R} \$ 3.833,82$ & $\mathrm{R} \$ 3.385,70$ \\
\hline $\begin{array}{l}\text { Distrito } \\
\text { Federal }\end{array}$ & $\mathrm{R} \$ 4.596,67$ & $\mathrm{R} \$ 4.296,81$ & $\mathrm{R} \$ 7.768,74$ & $\mathrm{R} \$ 9.078,46$ & $\mathrm{R} \$ 9.279,12$ & $\mathrm{R} \$ 9.864,10$ \\
\hline $\begin{array}{l}\text { Espirito } \\
\text { Santo }\end{array}$ & $\mathrm{R} \$ 3.807,68$ & $\mathrm{R} \$ 3.062,71$ & $\mathrm{R} \$ 3.293,17$ & $\mathrm{R} \$ 6.672,50$ & $\mathrm{R} \$ 8.543,41$ & $\mathrm{R} \$ 8.404,32$ \\
\hline Goiás & $\mathrm{R} \$ 3.288,29$ & $\mathrm{R} \$ 3.237,20$ & $\mathrm{R} \$ 3.974,88$ & $\mathrm{R} \$ 6.080,55$ & $\mathrm{R} \$ 7.277,38$ & $\mathrm{R} \$ 7.946,82$ \\
\hline Maranhão & $\mathrm{R} \$ 1.929,41$ & $\mathrm{R} \$ 2.029,23$ & $\mathrm{R} \$ 6.678,36$ & $\mathrm{R} \$ 4.396,49$ & $\mathrm{R} \$ 8.501,34$ & $\mathrm{R} \$ 8.162,27$ \\
\hline Mato Grosso & $\mathrm{R} \$ 3.140,19$ & $\mathrm{R} \$ 2.620,86$ & $\mathrm{R} \$ 6.049,30$ & $\mathrm{R} \$ 6.830,92$ & $\mathrm{R} \$ 6.351,76$ & $\mathrm{R} \$ 6.127,41$ \\
\hline $\begin{array}{l}\text { Mato Grosso } \\
\text { do Sul }\end{array}$ & $\mathrm{R} \$ 5.479,30$ & $\mathrm{R} \$ 4.047,35$ & $\mathrm{R} \$ 7.372,15$ & $\mathrm{R} \$ 8.098,49$ & $\mathrm{R} \$ 7.383,87$ & $\mathrm{R} \$ 4.084,06$ \\
\hline Minas Gerais & $\mathrm{R} \$ 2.247,92$ & $\mathrm{R} \$ 2.657,88$ & $\mathrm{R} \$ 5.288,04$ & $\mathrm{R} \$ 5.838,73$ & $\mathrm{R} \$ 7.207,48$ & $\# \mathrm{~V} \mathrm{ALOR!}$ \\
\hline Para & $\mathrm{R} \$ 1.614,35$ & $\mathrm{R} \$ 1.498,34$ & $\mathrm{R} \$ 3.630,09$ & $\mathrm{R} \$ 5.340,83$ & $\mathrm{R} \$ 5.401,83$ & $\mathrm{R} \$ 5.134,18$ \\
\hline Paraíba & $\mathrm{R} \$ 2.052,03$ & $\mathrm{R} \$ 1.573,17$ & $\mathrm{R} \$ 3.571,45$ & $\mathrm{R} \$ 4.763,08$ & $\mathrm{R} \$ 4.627,27$ & $\mathrm{R} \$ 5.941,34$ \\
\hline Paraná & $\mathrm{R} \$ 2.334,75$ & $\mathrm{R} \$ 2.303,38$ & $\mathrm{R} \$ 3.658,70$ & $\mathrm{R} \$ 4.331,87$ & $\mathrm{R} \$ 6.544,78$ & $\mathrm{R} \$ 7.063,97$ \\
\hline Pernambuco & $\mathrm{R} \$ 1.983,69$ & $\mathrm{R} \$ 2.187,11$ & $\mathrm{R} \$ 5.499,35$ & $\mathrm{R} \$ 7.591,35$ & $\mathrm{R} \$ 9.739,09$ & $\mathrm{R} \$ 10.697,79$ \\
\hline & & & & & $(\mathrm{CONTINUA)}$ \\
\hline
\end{tabular}


QUALIDADE DA EDUCAÇÃO NAS ESCOLAS PÚBLICAS NO BRASIL: UMA ANÁLISE DA RELAÇÃO INVESTIMENTO POR ALUNO E DESEMPENHO NAS AVALIAÇÕES NACIONAIS

(CONTINUAÇÃO)

\begin{tabular}{|l|c|c|c|c|c|c|}
\hline Piauí & $\mathrm{R} \$ 2.776,78$ & $\mathrm{R} \$ 2.885,17$ & $\mathrm{R} \$ 4.144,84$ & $\mathrm{R} \$ 5.217,13$ & $\mathrm{R} \$ 4.015,51$ & $\mathrm{R} \$ 1.588,09$ \\
\hline $\begin{array}{l}\text { Rio de } \\
\text { Janeiro }\end{array}$ & $\mathrm{R} \$ 3.337,26$ & $\mathrm{R} \$ 7.807,07$ & $\mathrm{R} \$ 9.491,80$ & $\mathrm{R} \$ 8.365,02$ & $\mathrm{R} \$ 5.364,62$ & $\mathrm{R} \$ 6.327,99$ \\
\hline $\begin{array}{l}\text { Rio Grande } \\
\text { do Norte }\end{array}$ & $\mathrm{R} \$ 2.642,68$ & $\mathrm{R} \$ 1.738,09$ & $\mathrm{R} \$ 4.750,72$ & $\mathrm{R} \$ 4.106,33$ & $\mathrm{R} \$ 5.127,99$ & $*$ \\
\hline $\begin{array}{l}\text { Rio Grande } \\
\text { do Sul }\end{array}$ & $\mathrm{R} \$ 2.672,31$ & $\mathrm{R} \$ 1.962,75$ & $\mathrm{R} \$ 3.524,78$ & $\mathrm{R} \$ 5.181,96$ & $*$ & $*$ \\
\hline Rondônia & $\mathrm{R} \$ 2.363,55$ & $\mathrm{R} \$ 2.249,27$ & $\mathrm{R} \$ 5.264,77$ & $\mathrm{R} \$ 5.931,40$ & $\mathrm{R} \$ 5.700,91$ & $\mathrm{R} \$ 5.406,24$ \\
\hline Roraima & $\mathrm{R} \$ 4.010,64$ & $\mathrm{R} \$ 4.737,35$ & $\mathrm{R} \$ 8.440,08$ & $\mathrm{R} \$ 7.415,05$ & $\mathrm{R} \$ 9.415,14$ & $\mathrm{R} \$ 8.221,59$ \\
\hline $\begin{array}{l}\text { Santa } \\
\text { Catarina }\end{array}$ & $\mathrm{R} \$ 3.300,89$ & $\mathrm{R} \$ 2.289,35$ & $\mathrm{R} \$ 4.330,89$ & $\mathrm{R} \$ 4.573,32$ & $\mathrm{R} \$ 5.350,12$ & $\mathrm{R} \$ 6.005,24$ \\
\hline São Paulo & $\mathrm{R} \$ 3.450,90$ & $\mathrm{R} \$ 3.568,40$ & $\mathrm{R} \$ 5.858,26$ & $\mathrm{R} \$ 5.555,96$ & $\mathrm{R} \$ 4.553,64$ & $\mathrm{R} \$ 6.213,54$ \\
\hline Sergipe & $\mathrm{R} \$ 2.974,96$ & $\mathrm{R} \$ 2.635,14$ & $\mathrm{R} \$ 3.458,31$ & $\mathrm{R} \$ 4.542,59$ & $\mathrm{R} \$ 4.855,29$ & $\mathrm{R} \$ 4.172,53$ \\
\hline Tocantins & $\mathrm{R} \$ 3.432,60$ & $\mathrm{R} \$ 2.458,85$ & $\mathrm{R} \$ 5.667,11$ & $\mathrm{R} \$ 5.792,54$ & $\mathrm{R} \$ 6.444,16$ & $\mathrm{R} \$ 5.929,67$ \\
\hline
\end{tabular}

* Informação não disponível.

** Diante da inexistência de informações para o ano de 2004, para o ano de 2005 utilizou-se apenas o valor investido por aluno naquele ano.

Fonte: SIOPE (2016).

Após a execução do teste estatístico foi possível estimar os coeficientes da reta de regressão e construir a equação completa que representa a relação entre investimento por aluno e resultados do Ideb para os estados brasileiros no período da análise. A Tabela 3 contém os coeficientes obtidos pela regressão linear:

Tabela 3 - Coeficientes da regressão

\begin{tabular}{|l|l|l|l|l|l|l|}
\hline \multirow{2}{*}{ Indicador } & \multicolumn{2}{|l|}{ Coeficientes não normalizados } & $\begin{array}{l}\text { Coeficientes } \\
\text { normalizados }\end{array}$ & T & \multirow{2}{*}{ Sig. } \\
\cline { 2 - 5 } \multicolumn{2}{|l|}{} & B & Erro Padrão & Beta & & \\
\hline \multirow{2}{*}{1} & (Constante) & 3,236 & 0,126 & & 25,984 & 0,000 \\
\cline { 2 - 6 } & Investimentos & $1,2 \mathrm{E}-5$ & 0,000 & 0,434 & 6,001 & 0,000 \\
\hline
\end{tabular}

Fonte: desenvolvido pelos autores.

Os coeficientes não normalizados, que representam a medida com que o valor da variável independente contribui para o valor da variável dependente, expressam que em relação ao investimento por aluno, para cada real investido por aluno no ano, teria se obtido um incremento de 0,0012 pontos no Ideb. Já para o valor atribuído à constante, entende-se que, caso não se desembolsasse nenhum acréscimo ao valor por aluno ao longo dos anos, o Ideb médio seria de 3,236 pontos por estado. A equação que descreve esse comportamento dessa relação entre as variáveis está ilustrada no Quadro 6.

Quadro 6 - Equação da reta com os coeficientes definidos pelo teste de regressão

$$
0,03236+1,2 \cdot 10^{-5} G a_{e a}=I D E B_{e a}
$$

Fonte: desenvolvido pelos autores. 
A Tabela 4 mostra a capacidade de a variação ocorrida no investimento por aluno explicar o resultado obtido pelos estados no Ideb.

Tabela 4 - Sumário do Modelo

\begin{tabular}{|l|l|l|l|}
\hline Modelo & R & R-quadrado & Erro Padrão Estimado \\
\hline 1 & $0,434^{\mathrm{a}}$ & 0,189 & 0,63363 \\
\hline \multicolumn{4}{|l}{ a. Preditora: (Constante), Investimentos } \\
\hline
\end{tabular}

Fonte: desenvolvido pelos autores.

Ao correlacionar as variáveis obteve-se como coeficiente de determinação um R-quadrado de 0,189. Esse valor tem a função de indicar a capacidade preditiva do modelo testado. Nesse sentido, 18,9\% da variação do Ideb pode ser explicada pela variação do investimento por aluno no período. E que para essa associação, tem-se uma relação de força diretamente proporcional entre as variáveis, considerando que o valor assumido por R é maior que zero. Ou seja, em relação aos desempenhos obtidos pelos estados no Ideb, 18,9\% está positivamente relacionado à variação dos recursos investidos por aluno no período.

Quanto à significância do modelo, foram obtidos, através do teste de análise de variância (Anova), os valores descritos na Tabela 5.

Tabela 5 - Teste Anova

\begin{tabular}{|c|c|c|c|c|c|c|}
\hline \multicolumn{2}{|c|}{ Modelo } & \multirow{2}{*}{$\begin{array}{c}\text { Soma dos } \\
\text { Quadrados } \\
14,457\end{array}$} & \multirow{2}{*}{$\begin{array}{l}\text { df } \\
1\end{array}$} & \multirow{2}{*}{$\begin{array}{c}\begin{array}{l}\text { Média dos } \\
\text { Quadrados }\end{array} \\
14,457 \\
\end{array}$} & \multirow{2}{*}{$\begin{array}{l}\mathrm{F} \\
36,008 \\
\end{array}$} & \multirow{2}{*}{$\begin{array}{l}\text { Sig. } \\
\\
\quad, 000^{\mathrm{b}}\end{array}$} \\
\hline \multirow{3}{*}{1} & Regressão & & & & & \\
\hline & Residual & 62,230 & 155 & ,401 & & \\
\hline & Total & 76,687 & 156 & & & \\
\hline
\end{tabular}

Fonte: desenvolvido pelos autores.

$\mathrm{O}$ teste Anova resultou uma significância (sig.) inferior a 0,001. Para esses valores obtidos pelo teste de análise de variância, podemos concluir que o modelo é válido e significante. Isso se dá, uma vez que o valor de sig. é aproximadamente zero, o que quer dizer que, para qualquer nível de significância, os valores no Ideb são distintos, ou seja, existem diferenças significativas no desempenho do Ideb quando o investimento é diferente de zero para considerar o modelo válido. $\mathrm{O}$ mesmo pode ser concluído com base na estatística $\mathrm{F}$, que assumiu o valor 36,008 . Através desse valor atribuído a $\mathrm{F}$, a quantidade de variância sistemática nos dados com a quantidade de variância não-sistemática apresenta que o Ideb é sensível aos 
investimentos em MDE.

A relação entre os valores assumidos pelas variáveis e a reta gerada pela equação descrita no Quadro 6 pode ser visualizada no diagrama de dispersão ilustrado na Figura 2.

Figura 2 - Diagrama de dispersão do modelo

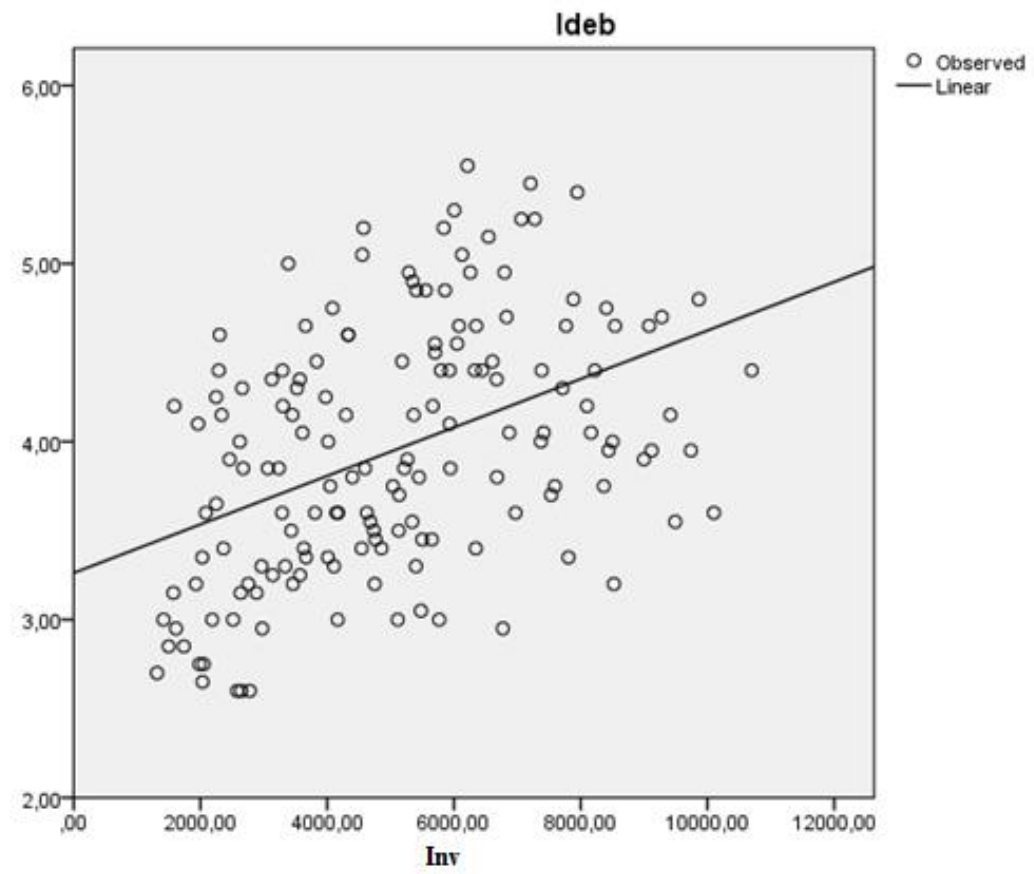

Fonte: desenvolvido pelos autores.

O diagrama de dispersão descrito na

Figura 2 representa a relação entre as duas variáveis contidas no modelo. A reta que transpassa os pontos consiste na representação no plano cartesiano da equação contida no Quadro 6, após ser ajustada linearmente pelo método dos mínimos quadrados. O eixo das abcissas (Inv), orientado horizontalmente, contém a escala de valores em reais investidos por aluno. O eixo das ordenadas (Ideb), orientado verticalmente, compõe-se pela escala de grandeza do Ideb. Cada ponto observado no diagrama consiste em uma associação de valores de investimento realizado e desempenho obtido para um determinado estado em um dos anos do período estudado.

Observa-se que a associação entre as variáveis dependentes e independentes é relativamente dispersa, devido ao desajustamento dos pontos quando comparados com a reta ou, ainda, quando observada a distância de determinado ponto em relação à reta. Apesar de se verificar essa moderada dispersão entre os valores associados e o modelo, observa-se a existência de uma tendência positiva de inclinação dos valores, mesmo para aqueles que se encontram mais distantes da linha de 
tendência. Em outros termos, de um modo objetivo, os resultados do Ideb tendem a ser maiores conforme ocorre o incremento dos investimentos.

Chama-se a atenção para o fato que a maior parte dos pontos que se concentra perto da reta, e que, consequentemente, são melhores explicados pelo modelo, situamse sinteticamente na área do gráfico que é delimitada pelos pontos cartesianos $(3,0$; 2.000,00) e $(4,0 ; 6.000,00)$. Porém, conforme os valores dos eixos Ideb e Inv vão aumentando, acentua-se o esvaziamento dos pontos em proximidade com a reta, e consequentemente, reduz-se a capacidade do modelo em explicar a relação existente para esses valores mais dispersos. Em outras palavras, entende-se que as elevações dos investimentos na escala de $\mathrm{R} \$ 2.000,00$ a $\mathrm{R} \$ 6.000,00$ explicam melhor a evolução do Ideb no intervalo de nota de 3,00 a 4,00, do que em relação a outros valores desembolsados. Isto significa que os investimentos são necessários e podem explicar a melhoria dos índices de aprendizagem, mensurados pelo Ideb, até certo nível. No entanto, a partir de determinado ponto, este investimento não se converte mais em melhoria dos resultados da aprendizagem, posto que os resultados do Ideb não são mais explicados pelo aumento de investimentos por aluno.
Do mesmo modo, o desempenho abaixo de 3,00 e superior a 4,00 no Ideb são menos explicados pelo investimento por aluno, dado o maior afastamento desses pontos em relação à reta. Nesse sentido, nota-se que em relação aos valores que superam 5,0 na escala do Ideb, praticamente inexiste explicação associada com a variável investimento, independentemente do valor assumido por esta. Evidencia-se também, que o valor de maior escala em relação ao eixo do Ideb é, justamente, o que possui maior distância relativa em comparação à reta. Isto é, a maior nota já obtida no Ideb por um estado não é explicado pelo investimento realizado.

O que se observa, portanto, é que os resultados das escolas de baixo desempenho podem ser explicados pelo mesmo modelo proposto por Coleman (1966), isto é, as características socioeconômicas seriam os fatores predominantes para influenciar o desempenho, e não apenas o uso dos recursos financeiros disponibilizados para as escolas. Esta aproximação teórica pode se dar até pelo próprio escopo da pesquisa de Coleman. Por outro lado, o desempenho médio das escolas tende a confirmar os resultados de Hanushek (2012) e de Hedges, Laine e Greenwald (1994, 1996a, 1996b), onde se verifica maior relação entre os fatores analisados. 
As contribuições individuais por estado para a formação completa do modelo descrito no Quadro 6, com a dispersão relativa por ente federativo organizado por região geográfica estão ilustradas nos Quadros 7, 8, 9, 10 e 11. E, neste caso, observa-se que quando são considerados apenas os pontos específicos por estado, as retas formadas possuem ajustamento individualizado superior ao modelo geral, cuja formação se deu pelo ajustamento de todos os pontos.

Quadro 7 - Dispersão dos estados da região Norte

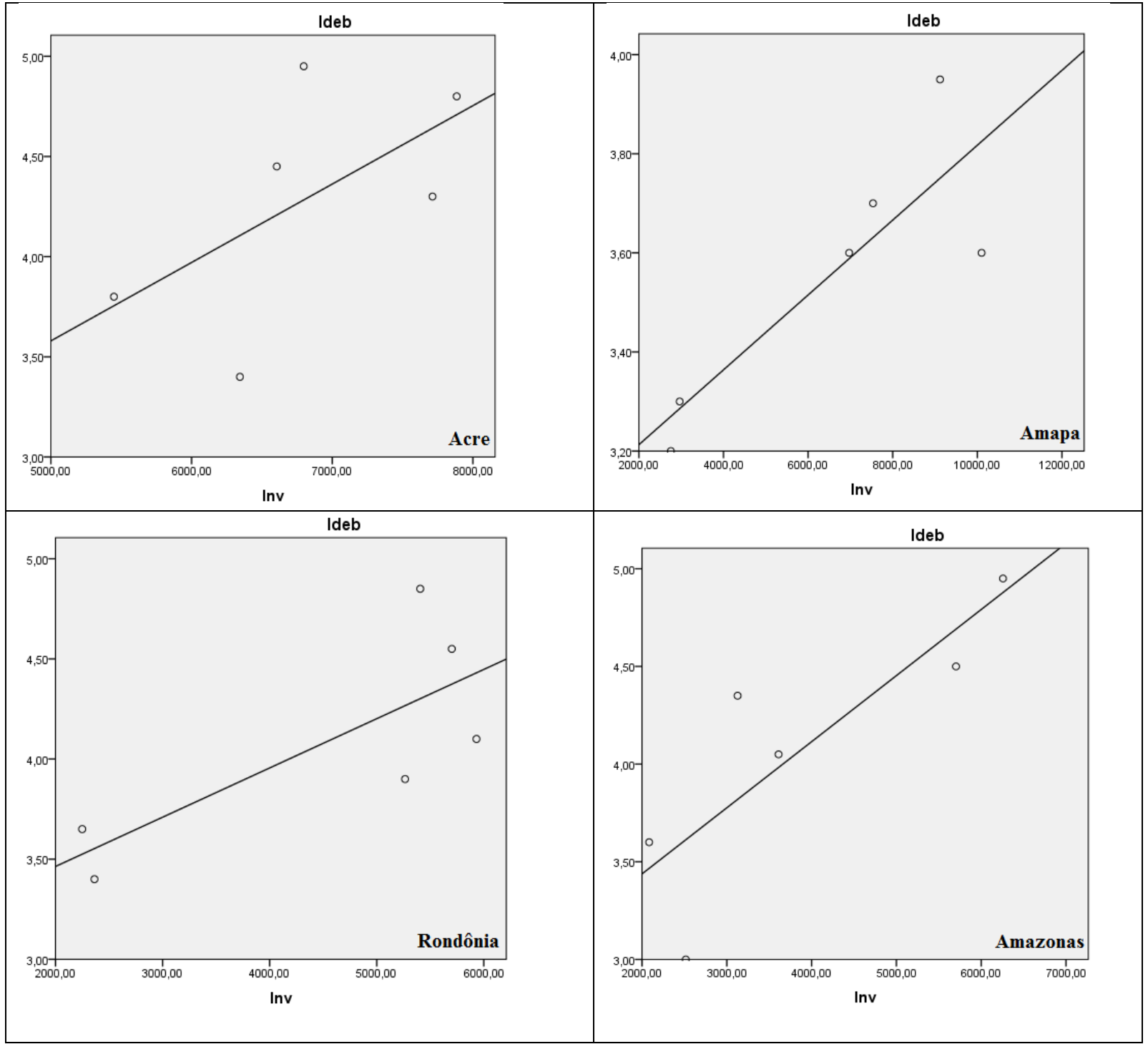




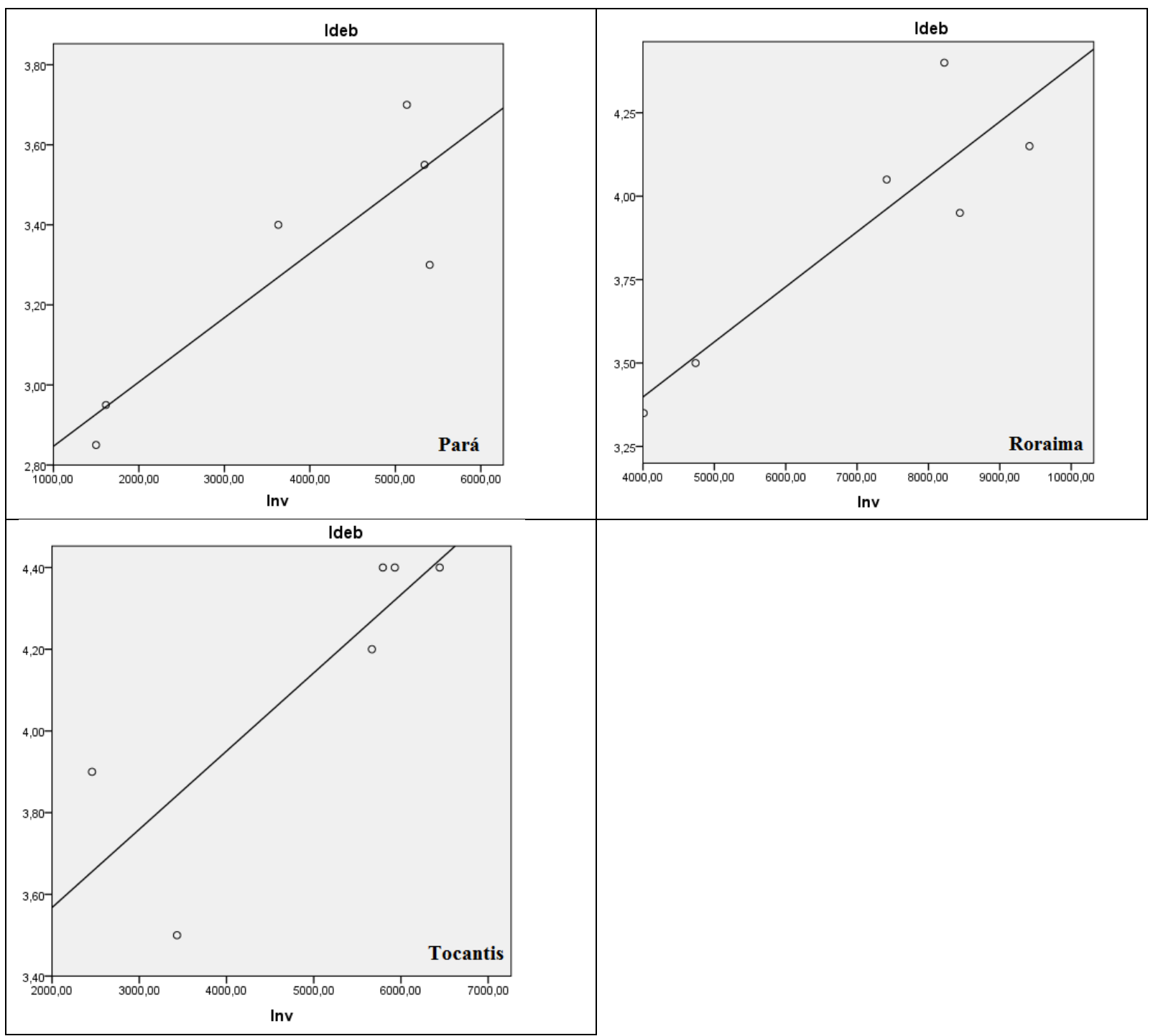

Fonte: desenvolvido pelos autores.

Para a região Norte, o gasto médio por aluno no período obteve crescimento de $101 \%$, passando de $\mathrm{R} \$ 3.320,57$, em 2005, para R $\$ 6.694,91 \mathrm{em} \quad 2015 . \quad \mathrm{Em}$ contrapartida, a evolução do Ideb foi de $36,24 \%$, subindo de 3,27 para 4,45 pontos. Quanto à capacidade de os investimentos explicarem os resultados no nível individual de agregação dos estados, com base no fator R-quadrado de cada curva, foi alta para o estado de Roraima (0,804), moderado para o Pará $(0,777)$, Amapá $(0,73)$, Tocantins $(0,703)$, Amazonas $(0,7)$, Rondônia $(0,588)$ e baixo para o Acre $(0,356)$. Os resultados sugerem que os recursos aplicados e a melhoria no Ideb ocorridos no estado de Roraima foram melhores relacionados quando comparados com os demais estados dessa região. 
Quadro 8 - Dispersão dos estados da região Nordeste

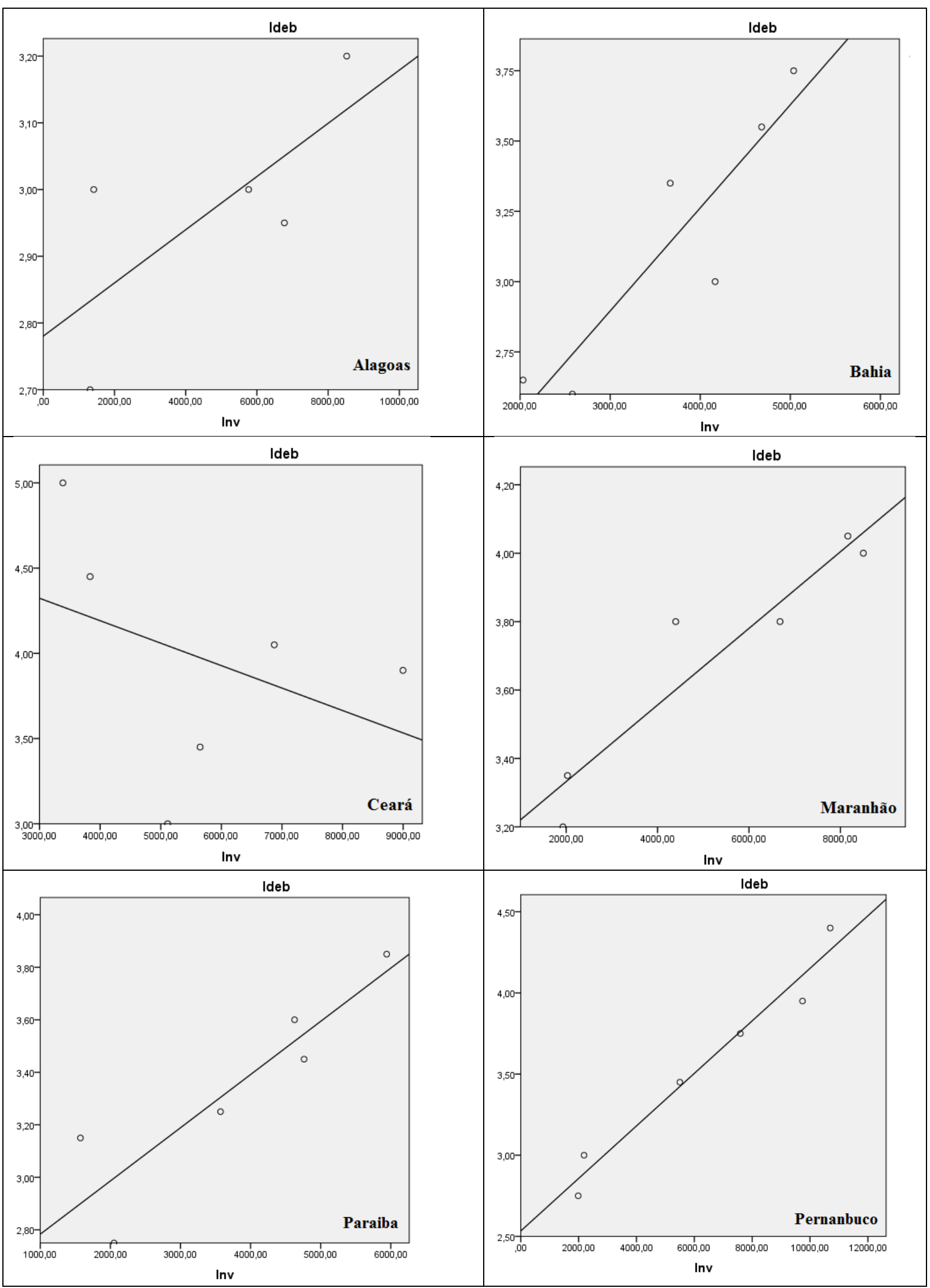




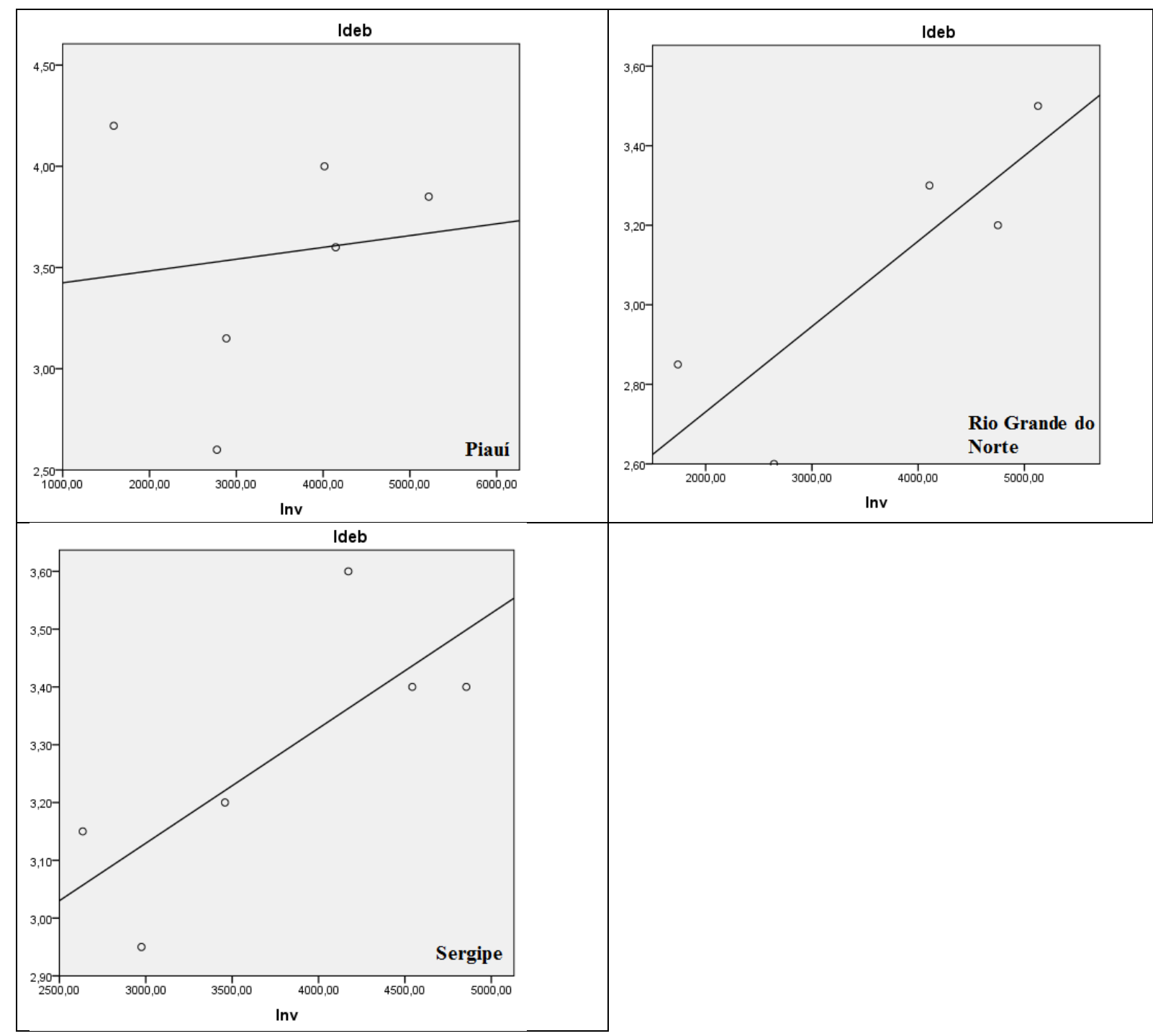

Fonte: desenvolvido pelos autores.

Na região nordeste, a trajetória de crescimento de recursos por aluno atingiu o equivalente $125 \%$, saltando de $\mathrm{R} \$ 2.596,55$ para $\mathrm{R} \$ 5.848,36$ de 2005 a 2015, e a média do Ideb evoluiu de 3,30 para 4,55, o que representa a um aumento de 44,33\%. Chama-se a atenção para o nível de correlação entre as variáveis nas curvas individuais ser quase perfeito para o estado de Pernambuco (R-quadrado=0,9636), significativamente alto para Maranhão $(0,895)$ e Bahia $(0,829)$, moderado para Paraíba $(0,799)$, Rio Grande do Norte $(0,73)$, Sergipe $(0,594)$ e Alagoas $(0,525)$, baixo para o Ceará $(0,147)$ e inexistente para o Piauí $(0,015)$. Os dados sugerem que na região Nordeste o estado de Pernambuco tem melhor capacidade de influenciar os resultados do Ideb pela alocação de recursos na educação. 
Quadro 9 - Dispersão dos estados da região Centro-Oeste

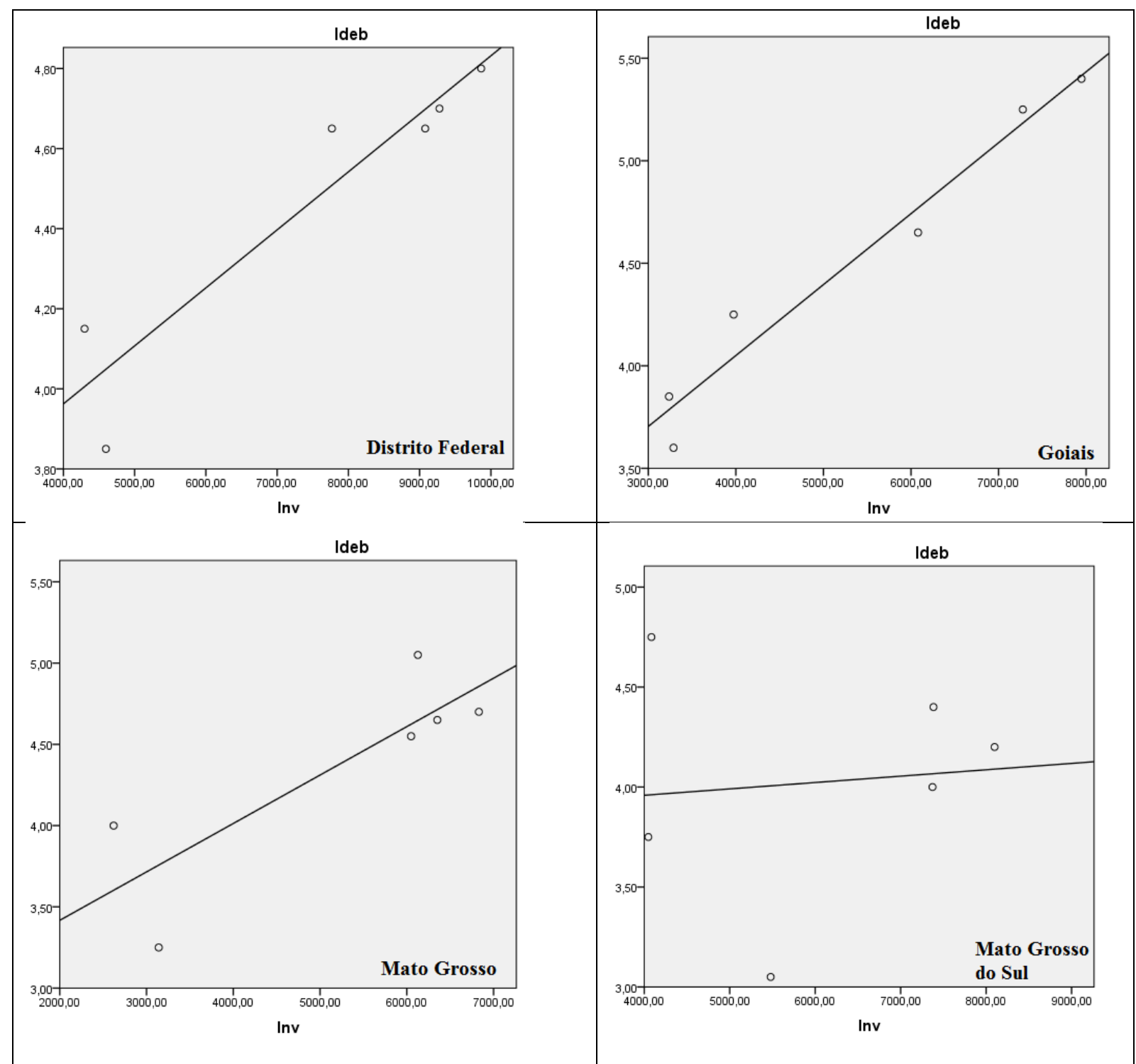

Fonte: desenvolvido pelos autores.

Para a região Centro-Oeste houve um crescimento de $70 \%$ no valor investido por aluno no período de análise, evoluindo de $\mathrm{R} \$ 4.126,11$ para $\mathrm{R} \$ 7.005,60$, seguido de um crescimento de $45 \%$ no Ideb médio, que foi de 3,42, em 2005, e passou para 4,60, em 2015. Quanto à capacidade de explicar a relação entre as variáveis, a relação foi forte para Goiás (R-quadrado=0,9598) e Distrito
Federal (0,882), moderada para Mato Grosso $(0,70)$ e inexistente para o Mato Grosso do Sul $(0,009)$. Os dados sugerem que o estado de Goiás parece ter investido melhor os recursos alocados à educação. Nesse sentido, no centro-oeste a relação investimento e desempenho está melhor relacionada no estado de Goiás. 
Quadro 10 - Dispersão dos estados da região Sudeste

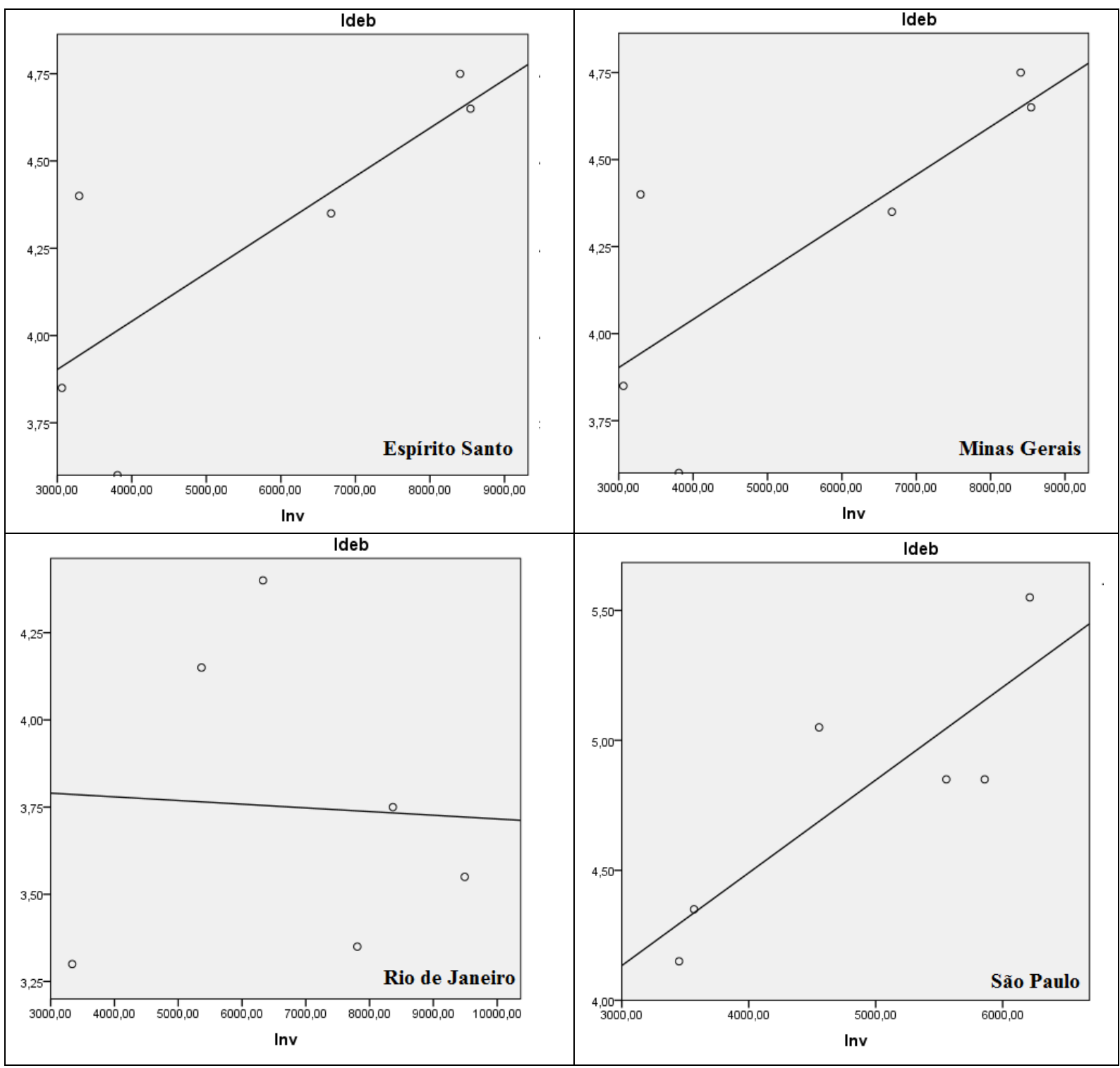

Fonte: desenvolvido pelos autores.

Do mesmo modo, a região Sudeste obteve um incremento de $119 \%$ no investimento médio por aluno, subindo de $\mathrm{R} \$ 3.210,94 \quad$ para $\mathrm{R} \$ 7.038,33$. O crescimento do Ideb, por sua vez, foi de $31 \%$, passando de 3,82 para 5,02. Em relação à capacidade de explicação, foi, praticamente, perfeita para Minas Gerais
(R-quadrado=0,992), moderada para São Paulo $(0,716)$ e Espírito Santo $(0,61)$ e inexistente para o Rio de Janeiro $(0,002)$. Sendo a melhor relação atribuída ao estado de Minas Gerais. 
Quadro 11 - Dispersão dos estados da região Sul

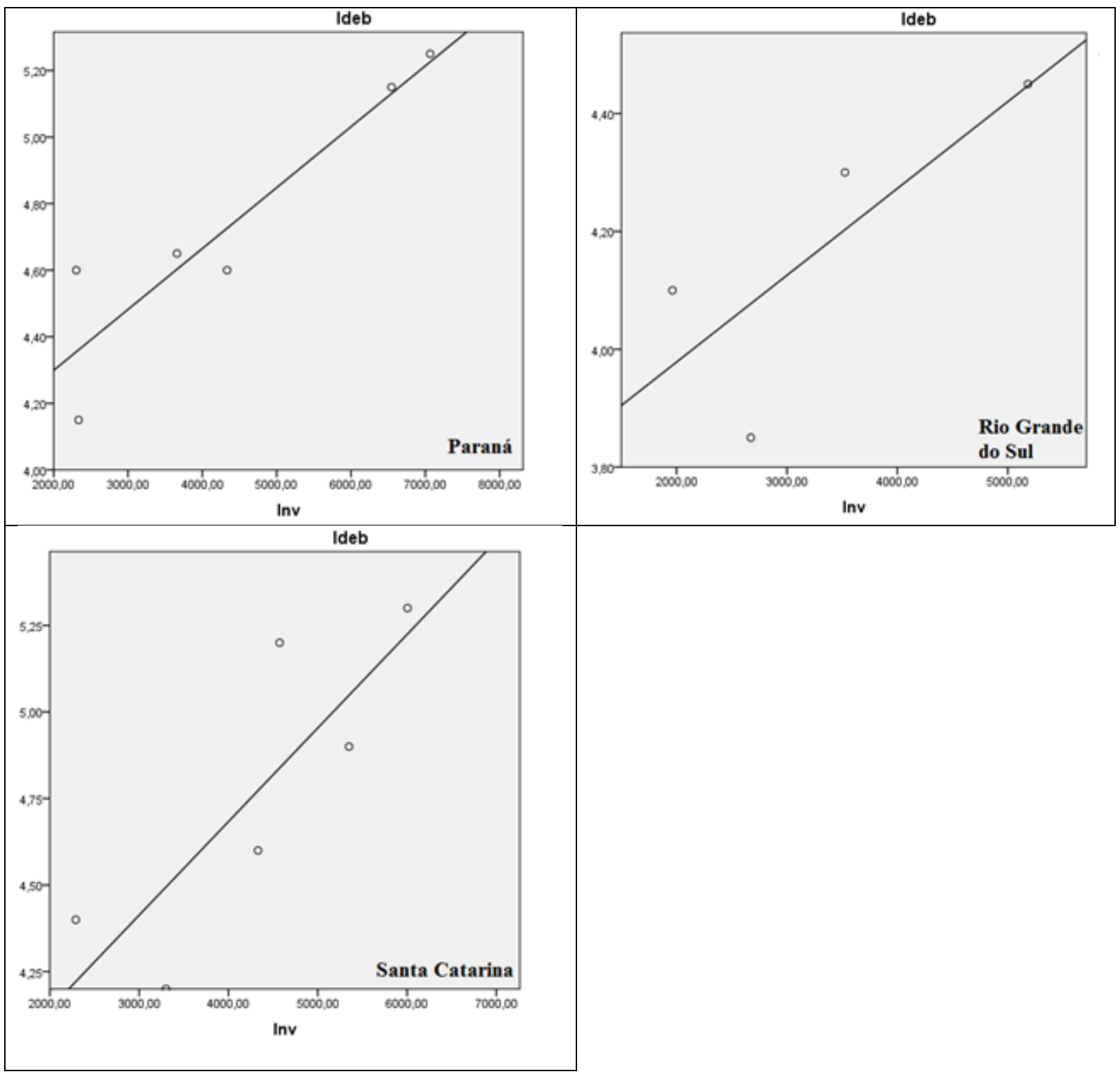

Fonte: desenvolvido pelos autores.

Para os estados da região sul o crescimento do investimento foi de $119 \%$, passando de $\mathrm{R} \$ 2.769,32$ para $\mathrm{R} \$ 6.083,72$. O incremento do Ideb, no entanto, foi de apenas $25 \%$, saindo de 4,06 para 5,1. Para a relação entre as variáveis, foi forte para o Paraná $(0,85)$ e moderada para Santa Catarina $(0,68)$ e Rio Grande do Sul $(0,618)$. Sendo Paraná o estado com maior correlação entre as variáveis estudadas.

Por fim, destaca-se que, nas análises regionais, a região Centro-Oeste foi a que realizou o menor incremento em termos de investimento por aluno e obteve, em contrapartida, a maior variação no Ideb. Entretanto, faz-se necessário lembrar que cada uma das regiões aplicou um esforço distinto para a melhoria do desempenho de 
suas escolas, partindo de valores de desempenho e investimentos peculiares às suas realidades. Desse modo, devido aos diferentes níveis de eficiência, mesmo se o modelo geral fosse realizado apenas com os dados daqueles estados com alta correlação no nível individual, ainda teríamos alta dispersão entre os pontos.

\section{CONSIDERAÇÕES FINAIS}

A partir da adoção da perspectiva econômica da educação, cuja abordagem assume que a qualidade da educação pode ser verificada através da eficácia do uso dos recursos disponíveis, buscou-se analisar a correlação entre investimento por aluno no âmbito do ensino fundamental, de 2005 a 2015 (desde o início da série histórica até a última avaliação, em 2015), e os resultados do desempenho dos estudantes obtidos nas avaliações nacionais. Mais especificamente, observou-se a correlação entre investimento por aluno e o Índice de Desenvolvimento da Educação Básica (Ideb) de cada estado como indicador de desempenho dos estudantes. Para o desenvolvimento da pesquisa, foi utilizada a regressão linear, pois possibilitou verificar a correlação entre variáveis dependente e independente, através da construção de um modelo linear definido pela equação de uma reta ajustada pelo método dos mínimos quadrados (HAIR et. al, 1998).

Nesse sentido, considerando o ponto de partida de cada rede estadual, verificouse que, nas regiões Norte, Nordeste, CentroOeste, Sudeste e Sul, as redes com melhores usos dos recursos disponíveis foram as de Roraima, Pernambuco, Goiás, Minas Gerais e Paraná, respectivamente. No cômputo geral, observa-se que, quando o ranking de melhor uso dos recursos disponíveis, de acordo com a correlação estabelecida, é construído considerando os estados isoladamente, verifica-se que Minas Gerais, Pernambuco e Goiás se destacam, enquanto Mato Grosso do Sul, Piauí, Ceará e Rio de Janeiro não apresentaram correlação entre os investimentos por aluno com o desempenho do Ideb.

Isso significa que os investimentos são necessários e podem explicar a melhoria dos índices de aprendizagem, mensurados pelo Ideb, até certo nível. No entanto, a partir de determinado ponto, tal investimento não se converte mais em melhoria dos resultados da aprendizagem, posto que os resultados do Ideb não são mais explicados pelo aumento de investimentos por aluno. Os resultados encontrados nas redes estaduais públicas brasileiras são similares àqueles observados por Hanushek (2005; 2012), ou seja, os níveis mínimos de recursos são necessários 
e valiosos na promoção da aprendizagem dos alunos, porém não são encontradas relações consistentes ou sistemáticas entre o desempenho dos alunos (mensurado pelo aproveitamento em testes de avaliação de rendimento escolar aplicados em universos de estudantes de diversas escolas, tais como as avaliações nacionais do Brasil, como o Ideb) e investimentos por aluno.

Os resultados aqui obtidos pelo teste estatístico apresentam que a representatividade do investimento no resultado do Ideb foi de pouco mais de $18 \%$. Esse número representa que, ao correlacionar as variáveis, obteve-se como coeficiente de determinação um Rquadrado de 0,189. Esse valor tem a função de indicar a capacidade preditiva do modelo testado. Nesse sentido, 18,9\% da variação do Ideb pode ser explicada pela variação do investimento por aluno no período. Para essa associação, tem-se uma relação de força diretamente proporcional entre as variáveis, considerando que o valor assumido por R é maior que zero. Ou seja, em relação aos desempenhos obtidos pelos estados no Ideb, 18,9\% estão positivamente relacionados à variação dos recursos investidos por aluno no período.

Em outras palavras, diante de um país do tamanho do Brasil, faz-se necessário acompanhar com maior proximidade as redes educacionais, visto que elas apresentam resultados de aprendizagem bem diferentes, apesar de os investimentos por aluno serem bastante similares. De acordo com Hanushek e Wößmann (2007, p. 14), “infelizmente, análises simples e sofisticadas produzem a mesma resposta: meras políticas de investimentos de recursos que adotam a estrutura já existente das operações escolares não são suficientes para levar a melhorias necessárias na aprendizagem". Isto é, faz-se necessário dedicar muito mais atenção ao uso dos recursos do que ao montante investido.

Por outro lado, a inexistência de relação significativa para os estados do Rio de Janeiro, Mato Grosso de Sul e Piauí podem estar associados a outros fatores que precisam ser melhor compreendidos em futuras pesquisas. Na coleta de dados, por exemplo, observou-se que esses estados utilizavam, no balanço orçamentário, a conta "outras despesas com educação básica", não separando os recursos por modalidade de ensino. Esse fator pode ter sido responsável pela falta de relação estudada para esses estados e, ao mesmo tempo, pode indicar falta de transparência com os recursos destinados à educação.

Chama-se a atenção, ainda, para aqueles estados cujo investimento por aluno era significativamente baixo em 2005 e 
possuíam Ideb entre 3,0 e 4,0 e que, ao aplicarem mais recursos para manutenção e desenvolvimento do ensino, obtiveram certo nível de incremento no desempenho nacional explicado pelo modelo testado. Porém, a mesma perspectiva não foi observada quando analisados os estados com maior gasto médio, assim como para aqueles com desempenho mais elevados. Nesse sentido, sugere-se para próximas pesquisas buscar analisar as redes individualmente e, mesmo, comparar escolas com altos e baixos desempenhos que tenham recebido recursos similares. 


\section{REFERÊNCIAS}

ADELSBERGER, H. H.; KINSHUK, P.; PAWLOWSKI, J. M.; SAMPSON, D. (Ed.). Handbook on information technologies for education and training. 2. ed. Hardcover, 2008.

ALVES, M. T. G.; SOARES, J. F. As pesquisas sobre o efeito das escolas: contribuições metodológicas para a Sociologia da Educação. Sociedade e Estado, v. 22, n. 2, p. 435-473, 2007.

ALVES, M. T. G.; SOARES, J. F. Contexto escolar e indicadores educacionais: condições desiguais para a efetivação de uma política de avaliação educacional. Educação e Pesquisa, São Paulo, v. 39, n. 1, p. 177-194, Mar. 2013. Disponível em <http://www.scielo.br/pdf/ep/v39n1/v39n1a12.pdf >

ARAÚJO, Raimundo L. S. Desvendando o Perfil dos Gastos Educacionais dos Municípios Brasileiros. Educação e Sociedade, Campinas, v. 33, n. 121, p. 1215-1233, out.-dez. 2012.

BAKER, Bruce D. Does Money Matter in Education? A Washington, DC: Albert Shanker Institute, 2016.

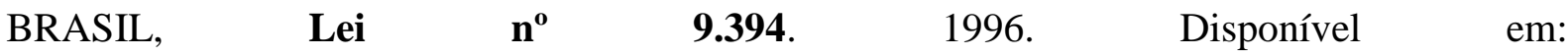
<www.planalto.gov.br/ccivil_03/leis/L9394.htm>. Acesso em: 02 out. 2016.

BRASIL, Constituição $\quad$ Federal. $1998 . \quad$ Disponível em: <www.planalto.gov.br/ccivil_03/constituicao/constituicaocompilado.htm>. Acesso em: 02 out. 2016.

BRASIL, Lei n. 11.494. 2007. Disponível em <www.planalto.gov.br/ccivil_03/_ato20072010/2007/lei/111494.htm>. Acesso em: 02 out. 2016.

BRASIL, Decreto Federal n. 6.253. 2007. Disponível em: <www.planalto.gov.br/ccivil_03/_ato2007-2010/2007/decreto/d6253.htm>. Acesso em: 02 out. 2016.

BRASIL, Portaria MEC $\mathbf{n}^{\mathbf{0}}$ 844. 2008. Disponível em: <http://www.fnde.gov.br/fnde/legislacao/portarias/item/3564-portaria-mec-n\%C2\%BA-844de-08-de-julho-de-2008>. Acesso em: 02 out. 2016. 
BRASINGTON, David M.; HAURIN, Donald R. Parents, peers, or school inputs: Which components of school outcomes are capitalized into house value? Regional Science and Urban Economics, v. 39, n. 5, p. 523-529, 2009.

BROOKE, Nigel; CUNHA, Maria Amália. A avaliação externa como instrumento da gestão educacional nos estados. Estudos e Pesquisas Educacionais, São Paulo, v. 2, p. 17-79, 2011. Disponível em: <http://www.fvc.org.br/estudos-e-pesquisas/livro-2-2011.shtml>. Acesso em 20 dez. 2012.

BROOKE, Nigel e SOARES, José. F. (Orgs.). Pesquisa em eficácia escolar: origem e trajetórias. Belo Horizonte: Editora UFMG, 2008.

CARD, D.; KRUEGER, A. B. School resources and student outcomes: an overview of the literature and new evidence from North and South Carolina. Journal of Economic Perspectives, v. 10, n. 4, p. 31-50, 1996.

CHILAND, C. L'enfant de 6 ans et son avenir. Paris: PUF, 1971.

COLEMAN, J.S.; CAMPBELL, E.Q.; HOBSON, C.J.; MCPARTLAND, J.; MOOD, A.M.; WEINFELD, F.D. and YORK, R.L. Equality of Educational Opportunity. Washington, US Government Printing Office, 1966.

DAVIES, Nicholas. A Fiscalização das Receitas e Despesas do Ensino em Minas Gerais. Cadernos de Pesquisa, São Paulo, v.43, n.149, p.518-54, maio/agosto 2013 a.

DAVIES, Nicholas. Educação do Distrito Federal perdeu bilhões com erros do Tribunal de Contas. Linhas Críticas, Brasília, vol. 19, núm. 39, mai-ago, 2013b, pp. 355-372. Disponível em: <http://www.redalyc.org/articulo.oa?id=193528369006>.

DAVOK, Delsi Fries. Qualidade em educação. Avaliação, Campinas; Sorocaba, São Paulo, v. 12, n. 3, p. 505-513, set. 2007. Disponível em: <http://www.scielo.br/pdf/aval/v12n3/a07v12n3.pdf >.

DEKE, J. A Study of the impact of public school spending on postsecondary educational attainment using statewide school district refinancing in Kansas. Economics of Education Review, v. 22, n. 3, p. 275-284, Jun. 2003.

DEMO, Pedro. Ciências sociais e qualidade. São Paulo: ALMED, 1985. 
DEMO, Pedro. Educação e qualidade. 6. ed. São Paulo: Papirus, 2001.

FERNANDES, Reynaldo; GREMAUD, Amaury Patrick. Qualidade da educação: avaliação, indicadores e metas. Educação básica no Brasil - construindo o país do futuro. Rio de Janeiro: Elsevier, v. 1, p. 213-238, 2009.

FIGLIO, David. Measuring school performance: Promise and pitfalls. In: STIEFEL, L., Schwartz, A.E., Rubenstein, R., Zabel, J. (Eds.), Measuring School Performance and Efficiency: Implications for Practice and Research. Eye on Education, p. 119-136, 2004.

FIGLIO, D. Functional form and the estimated effects of school resources. Economics of Education Review, v. 18, n. 2, p. 241-252, Apr. 1999.

FIGLIO, David., KENNY, Lawrence. Public sector performance measurement and stakeholder support. J. Public Econ. 93, (9-10), p. 1069-1077, 2009.

FIGLIO, David., KENNY, Lawrence. Individual teacher incentives and student performance. J. Public Econ. 91 (5-6), p. 901-914, 2007.

GUEDES, G. N. de Oliveira; BAQUEIRO, D. F. de Andrade e LORDÊLLO, J. A. Carvalho. Equidade e eficácia escolar: histórico dos estudos. 2015. Disponível em: $<$ http://www.equidade.faced.ufba.br/sites/equidade.oe.faced.ufba.br/files/equidade_e_eficacia _escolar_-_historico_dos_estudos.pdf $>$.

HAIR, J.F., ANDERSON, R.E., TATHAM, R.L. and BLACK, W.C. Multivariate Data Analysis. Upper Saddle River, New Jersey: Prentice-Hall, 1998.

.Education and the nation's future. In: SHULTZ, George P. Blueprint for America. p. 89-108. Stanford, California: Hoover Institution Press Publication, 2016.

.Economic growth in developing countries: The role of human capital. Economics of Education Review, 37, 204-212, 2013.

Education quality and economic growth. In: BRENDAN, Miniter. The 4 percent solution: Unleashing the economic growth America needs. New York: Crown Business, p. 227$239,2012$.

Some US evidence on how the distribution of educational outcomes can be changed. In: WOESSMANN, Ludger; PETERSON, Paul E. Schools and the equal opportunity problem. Cambridge: The MIT Press, p. 159-190, 2007. 
Economic outcomes and school quality. International Academy of Education. International Institute for Educational Planning. Belgium/France: Stedi Média, 2005.

.Making Schools Work: Improving Performance and Controlling Costs. Washington, D.C.: The Brookings Institution, 1994.

.The impact of differential expenditures on school performance. Educational Researcher, v. 18, n. 4, p. 45-51, 1989.

The economics of schooling: production and efficiency in public schools. Journal of Economic Literature, v. 24, p. 1141-1177, 1986.

., RIVKIN, S.G., TAYLOR, L.L. Aggregation and the estimated effects of school resources. Review of Economics and Statistics, 78 (4), 611-627, 1996.

; WÖßMANN, Ludger. Schooling, educational achievement, and the Latin American growth puzzle. Journal of Development Economics, v. 99, p.497-512, 2012.

.; WÖßMANN, Ludger. Education and Economic Growth. In: PETERSON, P.; BAKER, E.; McGAW, B. (Editors), International Encyclopedia of Education. V.2, pp. 245-252. Oxford: Elsevier, 2010.

; WÖßMANN, Ludger. Education Quality and Economic Growth. The International Bank for Reconstruction and Development / The World Bank. Washington DC, 2007.

HAURIN, Donald. R. e BRASINGTON, David M. The impact of school quality on real house prices: Interjurisdictional effects, Journal of Housing Economics, v.5, n.4, 351-368. 1996.

HEDGES, L.; LAINE, R. D.; GREENWALD, R. Does money matter? A meta-analysis of the effects of differential schools inputs on student outcomes. Educational Researcher, v. 23, n. 3, p. 5-14, Apr. 1994.

HEDGES, L.; LAINE, R. D.; GREENWALD, R. The effect of school resources on student achievement. Review of Educational Research, v. 66, p. 361-396, 1996a. 
HEDGES, L.; LAINE, R. D.; GREENWALD, R. Interpreting research on school resources and student achievement: a rejoinder to Hanushek. Review of Educational Research, v. 66, p. 411416, $1996 b$.

INSTITUTO NACIONAL DE ESTUDOS E PESQUISAS EDUCACIONAIS ANÍSIO TEIXEIRA (INEP). Avaliações da aprendizagem. 2011. Disponível em: $<$ http://portal.mec.gov.br/mais-educacao/190-secretarias-112877938/setec1749372213/18843-avaliacoes-da-aprendizagem>. Acesso em: 02 out. 2016.

INSTITUTO NACIONAL DE ESTUDOS E PESQUISAS EDUCACIONAIS ANÍSIO TEIXEIRA (INEP). Ideb. 2016. Disponível em: ideb.inep.gov.br. Acesso em: 02 out. 2016.

JENCKS, Christopher. Inequality, a reassessment of the effect of family and schooling in America. New York: Basic Books, 1972.

$\mathrm{KIM}, \mathrm{H}$. Is there a crowding-out effect between school expenditure and mother's child care time? Economics of Education Review, v. 20, n. 1, p. 71-80, Feb. 2001.

NASCIMENTO, P. A. M. School Resources and Student Achievement: Worldwide Findings and Methodological Issues. Educate - Especial Issue, p. 19-30, mar., 2008.

NASCIMENTO, P. A. M. Recursos destinados à educação e desempenho escolar: uma revisão na literatura internacional. Estudos em Avaliação Educacional, v. 18, n. 36, jan./abr. 2007.

PAWLOWSKI, J. M. The quality adaptation model: adaptation and adoption of the Quality Standard ISO/IEC 19796-1 for Learning, Education, and Training. Summary, 2007.

PLOWDEN Report. Central Advisory Council for Education. Children and their primary schools. London: HMSO, 1967.

RIBEIRO, V.; GUSMÃO, J. B. B. de. Uma leitura dos usos dos indicadores da qualidade na educação. Cadernos de Pesquisa, v. 40, n. 141, p. 823-847, 2010.

SANDER, B. Administração da educação no Brasil: é hora da relevância. Educação Brasileira, Brasília, v. 4, n. 9, p. 8-27, $2^{\circ}$ sem. 1982. Disponível em: <http://bennosander.com/publicacao_detalhe.php?cod_texto=21 >. 
SANDER, B. Gestão da educação na América Latina: construção e reconstrução do conhecimento. Campinas, SP: Autores Associados, 1995.

SAVIANI, D. A nova lei da educação: trajetória, limites e perspectivas. 7. ed. Campinas: Autores Associados, 2001.

SCRIVEN, M. Evaluation thesaurus. 4. ed. Newbury Park, CA: Sage, 1991.

Sistema de Informações sobre Orçamentos Públicos em Educação (SIOPE). Relatórios estaduais. 2016. Disponível em: <http://www.fnde.gov.br/fnde-sistemas/sistema-siopeapresentacao/siope-relatorios-estaduais>. Acesso em: 02 out. 2016.

TAVARES JÚNIOR, F.; NEUBERT, L. F. A qualidade da educação e a disseminação de sistemas de avaliação. Estudos em Avaliação Educacional, São Paulo, v. 25, n. 59, p. 22-48, set./dez. 2014.

VIEBRANTZ, R.; MOROSINI, M. C. Qualidade e educação superior: a norma de qualidade para a aprendizagem, educação e formação - ISO/IEC 19796-1. Educação, Porto Alegre, v. 32, n. 3, p. 277-285, set./dez. 2009. Disponível em: $<$ http://flacso.redelivre.org.br/files/2012/07/527.pdf $>$.

WÖßMANN, Ludger. Schooling resources, educational institutions, and student performance: the international evidence. Kiel Institute of World Economics, 2000.

WÖßMANN, Ludger. Why Students in Some Countries Do Better. Education Matters, n. 1, v. 2, p. 67-74, 2001.

WÖßMANN, Ludger. Schooling Resources, Educational Institutions, and Student Performance: The International Evidence. Oxford Bulletin of Economics and Statistics, v. 65, n. 2, p. 117-70, 2003.

WERLE, F. O. C.; KOETZ, C. M.; MARTINS, T. F. K. Escola pública e a utilização de indicadores educacionais. Educação, v. 38, n. 1, p. 99-112, jan.-abr. 2015. 